\title{
THE MBBS PROGRAMME IN NEPAL
}

\section{Dixit $\mathbf{H}^{1}$, Sharma S $\mathbf{C}^{1}$}

\section{ABSTRACT}

This article gives a comparison of the MBBS course that is being conducted by the three universities in Nepal. The course started by the Institute of Medicine was the pioneering effort. The concepts were taken a bit further at the time that the medical course at the B.P. Koirala Institute of Health Sciences (BPKIHS) was formulated. This teaching institution became partly responsible for the delivery of health care to certain areas of the country thus meeting the goal that the producers of health manpower were also involved in the delivery of health services to the community as well. With the starting of the medical course by Kathmandu University, this journey in the field of medical education was taken one more step forward. The involvement of private institutions also in the field of medical education meant that it was no longer just the responsibility of the government. Tribhuvan University also gave affiliations to private institutions in the medical field. The stage has now been extended by the starting of a medical course based totally on Problem Based Learning at the Kathmandu University Medical School or KUMS.

Key Words: MBBS, medical education, community oriented, system based, integrated.

\section{BACKGROUND}

The Institute of Medicine (IOM), intent on starting a medical course, started making a curriculum for the same in about 1976. When the course seemed likely to be started, special efforts were made to make a community oriented, systems based, integrated type of course. The entry to this course at that time was for people who had worked as middle level health workers. However, when this curriculum was introduced there was no clear idea as to what to call the course. The proposed degree was Master in Science Diploma of Doctor of General and Community Medicine (MSDDGCM). This degree would be equivalent to the basic medical degrees such as MBBS or MD as given by other universities or institutes. By the time that the students enrolled in the course had completed it, this proposed degree of Tribhuvan University (TU) had been designated as MBBS. However, because of various political distractions

1. Kathmandu Medical College, Sinamangal, Kathmandu, Nepal.

Address for correspondence : Dr. Hemang Dixit, Professor

Kathmandu Medical College, Kathmandu University

P.O. Box: 2730, Kathmandu, Nepal.

Phone: 413460, Email: hdixit@healthnet.org.np 
to the 4 years course started in 1978, the first products did not graduate till 1984. Even after this six-year stint, it was voiced that these locally trained doctors were second-class in that they had been specially trained for the rural areas and not comparable to those trained outside of the country. Doubt was laid as to whether, these doctors, the products of IoM would ever be recognised any where in the world. But all was well and by the time the products came out, the MBBS course conducted by the IoM was of four and half years duration with the mandatory one year of internship. It is now part of history, but the course is recognised by all the countries of the SAARC region that have Medical Councils. The products of IoM are recognised for limited registration by the General Medical Council (GMC) of the United Kingdom and are allowed to sit for the USMLE test of the United States of America. Following the Jana Andolan of 1989/90 it became possible to start medical colleges within Nepal. If anything, such a venture was looked at very liberally, paying scant attention to what may be the effect on the health manpower situation of the country.

Over the course of last ten years a number of colleges have come up and the tally is ten so far. The breakdown of the attachment or affiliations of the different colleges is as follows:

\section{Tribhuvan University (TU)}

1. Institute of Medicine - The first university of the country conducting MBBS course. This educational institution has the Ministry of Education as link ministry.

2. Universal College of Medical Sciences (UCMS), Bhairahawa - Private medical college affiliated to TU.

3. National Medical College, Birgunj - Private medical college affiliated to TU.

BP Koirala Institute of Health Sciences (BPKIHS)

Deemed University under the aegis of the Government with Ministry of Health as link ministry.
Kathmandu University (KU). Private university with a total of six medical colleges

1. Kathmandu University Medical School (KUMS). The new medical school of the university itself with a PBL approach and started in 2001.

2. Manipal College of Medical Sciences (MCOMS)- Affiliated college under KU.

3. Colleges of Medical Sciences - Nepal, Bharatpur. Affiliated college.

4. Kathmandu Medical College - Affiliated college of KU at Kathmandu.

5. Nepal Medical College - Affiliated college of $\mathrm{KU}$ at Kathmandu.

6. Nepalgunj Medical College - Affiliated college under KU.

The curriculum adopted by the three institutions, TU i.e. IoM, BPKIHS and KU are compared on the basis of subdivisions in the curriculum and hours of instruction allotted to the various subjects. BPKIHS and KU curriculums are found to be more simple and straightforward in presentation. Both these are also much more similar when compared to that of IoM in terms of their construction and outline.

\section{THE IOM CURRICULUM}

Before work was started on the MBBS curriculum for Nepal there was a survey of the districts of Tanau, Nuwakot and Bara in Nepal. These indicated the needs of the country and it was on these findings that the curriculum was based. Besides this, the curriculum is also based on the job requirements of the medical officer working in the districts of Nepal. ${ }^{1}$ To prepare the first version of the syllabus, there was extensive support by the WHO and the core curriculum was based on what was being done at McMaster. The first part of the curriculum was ready when the course started though the printed form of the full curriculum of 
the MBBS was finally brought out in 1984. It is interesting to note in this context that the first recommendations on medical education by the Nepal Medical Council (NMC) only came out in 1993. The NMC did not at the start have a syllabus of its own and in the early years stated that the "MBBS Curriculum of the Institute of Medicine would be the reference document of the NMC." It was much later that the first version of the MBBS curriculum was prepared by the NMC but it has not been printed yet. The Nepal Medical Council has legal authority to recognise medical qualifications and then to give registration. The $3^{\text {rd }}$ amendment of the NMC Act also set educational norms and standards and gave authority as well to review them as and when required. In connection with this the NMC brought out its recommendation for undergraduate medical education in 1995 (2).

Though the MBBS curriculum of the IoM was revised as from the $11^{\text {th }}$ batch of students in 1991, the printed form of the $2^{\text {nd }}$ version did not come out till 1994. Some sort of break down of hours for both the theory lectures and practical has been done as is depicted in this document. ${ }^{1}$ A more detailed breakdown of the MBBS courses is shown in Annexures A to F. The IoM divides it entire curriculum into 3 phases, Phase I, II and III. Phase I lasts for the first 2 years. Although the curriculum, as stated in the document, envisaged integrated teaching, the reality is that the pre clinical subjects are taught separately though some form of coordination is maintained by teaching the same system in the different subjects. The breakdown of the theory and the clinical is as shown in Annexure A. Phase II ( $3^{\text {rd }}$ year) lasts for one year. Phase III encompasses another one and half years. The total course of the IoM, gives a total of 7098 hours of which 1889 is for Basic Sciences and 5209 for Clinical Sciences. Annexure A (The second version of the curriculum states it to be 8221 hours) Following this there is a one-year period of compulsory rotating internship. The reason for this choice of internship was that the product of the IoM should have a workable knowledge in all areas of medicine and surgery and thus be capable to work in any area of Nepal.

\section{MBBS CURRICULUM AT BPKIHS}

The curriculum of the MBBS course at BPKIHS had its beginnings at a Seminar on Medical Education held in December 1993 and followed up by two other workshops in 1994 and 1995. The MBBS curriculum is integrated and incorporates the organ system and need based approach. It is community-oriented. It is partially problem based. ${ }^{4}$

BPKIHS divides its curriculum into 2 phases viz. Phase I and Phase II. Phase I lasts for 2 years and is subdivided into six units, $0,1,2,3,4$ and 5. Phase II starts from the $3^{\text {rd }}$ year till the end of the course i.e. end of four and half years. A total of 1685 hours is allotted in the first phase and 1754 hours in the second phase (100weeks@ 40hours/week). The total MBBS course is thus given as 3439 hours of instruction (Annexure - B). However a large number of hours are spent in the residential posting.

\section{MBBS CURRICULUM AT KU}

The first draft of the MBBS curriculum of KU for the Basic Sciences part of the curriculum was "synthesised" initially in 1994. This was developed in association with the Manipal Academy of Higher Education (MAHE), Manipal, India. In an effort to keep abreast of developments in modern medical education, the first review of the Basic Medical Sciences curriculum was done in 1996 in collaboration with Institute of Medicine of Tribhuvan University and MAHE of Manipal. This second version of the Basic Medical Sciences curriculum which had some modifications but 
retained the pattern of organ system coverage that was present in the original version was brought out in December, 1996 A subsequent workshop held in March 2002 emphasises the teaching of Basic Medical Science subjects in a system wise and integrated fashion.

KU divides its curriculum in Part I and Part II. Part I is for Basic Sciences and lasts for 2 years. Part I is subdivided into 4 units. Units I, II, III and IV. KU has allotted a total of 2267 hours of instruction and 502 hours of self-study in the first four units. KU gives a total of 1194 hours for the theory classes and 983 hours of practical classes. Besides this, 80 classes are allotted for clinical orientation, 30 hours in Medical Informatics and 502 hours are allotted for self-study. Medical informatics is one subject that is only found in the $\mathrm{KU}$ course of MBBS ( $5 \& 6$ ). On going through the documents it was found that the total hours of study in KU syllabus and two of the medical colleges attached to KU was as follows:

\begin{tabular}{|c|c|c|c|}
\hline & $\begin{array}{c}\text { BASIC } \\
\text { SCIENCES }\end{array}$ & $\begin{array}{c}\text { CLINICAL } \\
\text { SCIENCES }\end{array}$ & TOTAL \\
\hline KU & 2285 & 4248 & 6533 \\
\hline MCOMS & 2285 & 4200 & 6485 \\
\hline Nepal MC & 1826 & 4058 & 5884 \\
\hline KMC & 2277 & 5623 & 7900 \\
\hline
\end{tabular}

\section{See Annexure C to F.}

$\mathrm{KU}$ in its norm and standards for the MBBS programme that was brought out in August 1997 states quite categorically that "Not more than one third of the time allotted for each subject should be spent at didactic teaching" (7) With this fairly liberal attitude, stipulation that attendance less than $75 \%$ in any subject will bar a student from sitting for any examination then seems strange!

\section{ENTRY}

The current practise is that each of the three universities has a system of selection for entry into the MBBS course conducted by it. The Ministry of Education conducts yet another examination and also an interview to select candidates for the especially reserved seats in which the Ministry of Education can send the free scholarship students. The NMC has been stressing the need for a common entrance examination but this seems unlikely as each of the three authorities insist upon the right to conduct entrance examination. Whilst the sitting of such examinations is a nuisance and a stressful event for many prospective students, the reality is that it is a welcome opportunity to literally earn funds for the university conducting the tests.

The selection process has to be made better, for with the advent of the private medical schools, one of the criteria for admission is the capacity to pay for the medical education. (This is more so in cases of students who have gone to study medicine outside of the country, without the hassles of entrance examination). Currently some students are coming to study medicine because:

- their parents wanted them to study this

- there would be better marriage prospects if one was a doctor

Factors such as motivation to work in the health sector and communication skills are not major deciding factors.

A realistic solution to the question of entrance would be to allow any candidate who has appeared in any of the three university entrance examination and has passed it to be eligible to apply to any of the three universities. Subsequent selection can be on the basis of the marks in the entrance examination, interview performance, etc.

Another point is regards background. Whilst MBBS courses in some parts of the world encourage students of diverse backgrounds to take up medicine and are allowed to do so if they satisfy entry criteria, this is not so in Nepal. Here a background of 
science is essential and there is no provision for giving credit to a student who has some experience in the health sector.

\section{TEACHING / LEARNING ACTIVITIES}

At per the guidelines of the Nepal Medical Council, it is obligatory for all medical colleges in Nepal to have a teacher-training cell. Unfortunately however there is as yet no mechanism for proper selection of teachers for the particular institution concerned. There needs to be some sort of standardisation of the grades and number of faculty required for the different departments. Though NMC has recently set criteria of the number of teachers required for the different departments, this has still to be further regularised on the basis of the workload in terms of teaching required or services to be provided.

\section{EXAMINATION}

Tribhuvan University has delegated authority to the Institute of Medicine to arrange for the holding of the examinations at various stages of the MBBS course. External examiners from within and outside of the country are called for the final examinations of the different phases. .

BPKIHS had been initially helped by the All India Institute of Medical Sciences (AIIMS) to conduct the entrance and also the final examinations. Now whilst a number of external examiners come from Delhi, the BPKIHS also uses as externals some of the medical faculty attached to KU and TU.

KU has senior faculty from its various colleges and also from IoM and BPKIHS acting as external and internal examiners at various stages of the MBBS course.

\section{INTERNSHIP}

Some years ago, NMC stated criteria were included in the rules and hospitals were recognised for internship purposes. In the initial stages the hospitals in the capital were only listed. Subsequently, some hospitals recognised for internship were derecognised when it was pointed out that the person doing the supervision had been transferred from there. Similarly it was found that certain institutions were having more interns working there than the quota allowed for that particular institution. After a number of years of experience, the NMC felt able to publish a set guidelines for internship only in 2000. Prior to allowing internships at any institution, the NMC generally carried out an inspection of the particular hospital. The ability to absorb students for internship became more acute as many of the students doing medicine outside of Nepal, wanted for various reasons, to come home to do the internship. Having difficulty to accommodate the large number of students wanting to do internship in Nepal, the authorities that are, even put a notice in the papers saying that students should do the internship at the institution where they had done the medical course.

Thus the doing of internship is in a state of complete disorder. Whilst the Nepal Medical Council has described as many as five "internship schemes", it is the rotating one that is most utilised. There are however many shortcomings which may be listed as:

- inadequate supervision during the internship

- no set criteria of what is to be learnt during the course of the posting

- no requirement to keep a log book of what has been learnt and done

- no specific guidelines as to the load of work 
that should be there for the internship posting to be adequate.

\section{RECOGNITION}

This is at various stages. The MBBS degrees of IoM are recognised by all the countries of the SAARC region and the students from here are going not only to the UK and USA after fulfilling the entry requirements but also going elsewhere in the world. BPKIHS too has been recognised by India and some other SAARC countries. KU the most recent entrant in the medical education field has had its degree recognised by the Medical Councils of India and Sri Lanka. Students with MBBS from KU are also sitting for the USMLE and PLAB tests and thus have opportunities to go and work in both UK and the USA.

\section{DISCUSSION}

When BPKIHS and KU curriculum were compared in their Phase I and Part I respectively it was found that a total of 1194 hours of theory classes and 963 hours of practical classes are allotted by $\mathrm{KU}$ whereas 887 hours of theory and 793 hours of practical classes are allotted by BPKIHS. Moreover KU has allotted 80 hours of additional classes for clinical orientation, 30 hours for Medical Informatics and 336 hours for self-study in this curriculum in Part I. Anatomy has been given more emphasis in terms of hours of instructions allotted in both institutions. KU has given a total of 533 hours for Anatomy whereas BPKIHS has given 396 hours for the same. Similarly, Physiology and Biochemistry also get more hours in the KU curriculum as compared with the BPKIHS curriculum. Physiology gets 294 hours in KU and 269 hours in BPKIHS curriculum. In Biochemistry, the difference is more prominent when one notes that KU gives 300 hours whereas only 199 hours is given by BPKIHS. Pathology is given a total of
188 theory and 86 practical classes in KU curriculum whereas in BPKIHS it is 147 and 129 respectively. Microbiology gets 197, Pharmacology 255 and Community Medicine 304 hours of instruction in KU curriculum where the same subjects are given 229, 155 and 91 hours in BPKIHS curriculum.

It may be noted that the teaching of Basic Medical Sciences in an integrated, system wise and with a problem solving approach is the stated objective of all the three curriculums of TU, BPKIHS and KU. The degree of implementation varies from institution to institution and this is more due to unfamiliarity with the methods rather than opposition by the implementers. Even in the case of the IoM, although integrated teaching is mentioned in the curriculum, it is not practised for all the subjects are taught separately. Some correlation seminars are held. In the Phase I university final examination a combined theory paper is given but the practical examination in all the basic science subjects are held separately. What must be kept in mind is that except in the IoM there is, in all the other institutions, a fair amount of turnover of the faculty. Thus widespread use of educational methodology has still to be stabilised irrespective of whatever the implementers may claim. It thus remains to be seen as to how successfully the PBL methodology will be implemented at Kathmandu University Medical School or KUMS, the most recent entrant to the field of medical education in Nepal.

What is heartening in all this is that all the medical schools functioning under the aegis of the three universities of the country are to a certain extent based on modern thoughts of community oriented, system based and integrated teaching. The amount of instruction that is actually being carried out on the basis of these pious wishes is debatable. What is also apparent is that the 
medical education in this day and age is influenced by the practices that are currently in use, not only in the UK and the USA but also elsewhere in the world. The period following the jana andolan has been a very hectic period for medical education in Nepal. Besides the 10 medical colleges in the country, it is stated that there may be another five applications for the starting of medical colleges. What direction medical education will take in this country is therefore still not clear. Will the standard of health care improve or become worse in the future? Will there be cut throat competition and non-ethical practice?

Whilst each university formulated its own curriculum, the overall objective of all the MBBS courses is to produce a doctor who is aware of the health care requirements of Nepal. What needs to be looked at is whether the objectives of the course, the requirements for the teaching / learning process and the end result are in conformity with what was envisaged. The hope is that the authorities are not in their ivory towers, unaware of what is happening below.

What certainly need to be looked at are the standards and the capability of the teachers imparting the education. Have all the teachers be they faculty or otherwise, had some form of training or experience to guide the new students coming into training ? Have they all been appointed as per certain guidelines or is it at the whim of a certain individual ? Is there a method by which the performance of the appointees is assessed ? Are there opportunities to improve oneself and attain some form of career advancement? These are some of the questions that the universities ought to look at.

One of the realities considering our medical students is that many are not mature. A fair percentage of the students miss classes on the slightest pretext, avoid assessments, presentations and are thus very irregular in attendance. This may be related to not only the lack of motivation but also to the standard of teaching which is not interesting enough or not up to the standard. Perhaps it is related to the fact that with the advent of private medical education, one of the criteria for the selection of the student is the capacity to pay for the medical course.

In the MBBS course that was started by the IoM, the idea was that students should have become a middle level worker prior to doing the medical course. A study of such doctors with this background and others with ISc has shown that such doctors with a background of having worked as middle level workers in the health sector are more likely to go and serve in rural areas. ${ }^{8}$

Now that KUMS has started the PBL type of course, one option for this may be that only students who have a minimum of $15 / 16$ years of study viz. $10+2$ plus a 3 or 4 years Bachelor degree would be eligible for it. The Bachelor degree could be in Science or even Humanities. It could even be MSc in medically related subjects such as Anatomy, Physiology or even Biochemistry. Such a change would be in conformity the BBS and in the format of the MBA programme run by the KU and which in turn is compatible in with the practice in America. After all it is Harvard and other universities of USA, which are involved with the programme here. In such a way they would also be doing relevant research in medical education.

The final query as to which course conducted by which university is appropriate for Nepal can only be judged after an assessment of the products in various areas such as their performance in the licensing examination which the NMC has recently instituted, their working under supervision and 
ability to take decisions etc. It is however to early to be able to make a comparison on that score. One can therefore only say that "time alone will tell".

\section{ROLE OF NMC}

There is no doubt that the NMC has played a significant role in the development of medical education in Nepal. When the floodgates were let open and many players came to this sector, there were attempts from many quarters to try to control the set up of the organisations. There was talk of making individual colleges into autonomous institutions and even ideas were floated that some may not be under the purview of the NMC. Views have been expressed that with liberalisation, it was all right to allow institutions to be set up, but whether there was adequate justification, whether the institution survived or not was not the headache of the licensing body.

There were discussions too as to whether the NMC had the expertise to make a detailed curriculum specifying the hours of theory and clinical teaching and whether this was something, which should rightly be left to the universities conducting the MBBS course. It boiled down to the right of the university to start a particular medical course and the right of the NMC to see the it was done properly by setting guidelines for the same as stated by the Nepal Medical Council Act. ${ }^{2}$

Now that there has been legal sanction for having licensing examination, the question that is being asked is whether it is necessary for the NMC to inspect medical colleges on an yearly basis. Is the objective to ensure uniformity of medical education or to ensure a certain standard attained by the students of the different institutions? Perhaps some sort of scrutiny is necessary till the college attains permanent recognition. What happens after that, then ?
The answer to this may be the accreditation process that is being considered by the NMC. In this process the individual colleges are required to fill up questionnaires made available by the NMC and return the same to the Council. After duly studying these, the NMC sends a team to the College and on the basis of the findings the medical college is given accredition for a specified period. Hopefully such a system will come into force soon.

\section{CONCLUSION}

It is interesting that all the courses being presently conducted by the three Universities of Nepal are to a certain extent all community oriented. What the producers of these doctors must ensure is that all the graduates, from all the different institutions attached to their respective universities, must each be of a certain standard before they are declared as having graduated. The training must be thorough, assessments fair and extensive so that the doctors who graduate feel justly proud of their achievement and of their alma mater. They should be shining ambassadors for health care service anywhere in the world.

\section{ACKNOWLEDGEMENT}

Thanks are due to Prof. Ramesh Adhikari and Prof. Mohan Joshi of the IoM, Prof. Sudhamshu Khanal of BPKIHS, Prof. J.S. Nagra of MCOMS and Prof. Shekhar Babu Rizyal of Nepal Medical College, all of whom have very kindly looked at this article and given various suggestions. Thanks are due to Mr. Ranjit Singh Thapa and Mr. K. Shrinivas for all the secretarial work that has been undertaken in the preparation of this article. Any errors and mistakes remaining are the responsibility of the authors. The opinions expressed in the article are those of the authors and do not represent that of any Association, Council or University that they may belong or be attached to. 


\section{REFERENCES}

1. Innovative Programmes of Medical Education in South East Asia. 1993, WHO New Delhi.

2. Recommendation on Undergraduate Medical Education 1995, Nepal Medical Council.

3. Curriculum for MBBS. TU, IOM. 1994. Medical Education Dept. IoM, Kathmandu.

4. The First Version of the MBBS Curriculum 1996 BPKIHS, Ghopa, Dharan
5. MBBS Curriculum. Basic Medical Sciences, KU. Part One. Third Version. 2001

6. MBBS Curriculum. Clinical Sciences,KU. 1996.

7. KU Norms and Standards for MBBS Programme, $1^{\text {st }}$ version, August 1997.

8. Dixit, $\mathrm{H}$, Follow-up on health science students of IoM. Inst Med J. 1993, 15, 222-229 
SUBJECT WISE BREAK DOWN OF MBBS COURSE SEMESTER HOURS I - IX

Institute of Medicine

Annexures (A)

\begin{tabular}{|c|c|c|c|c|c|c|c|c|c|c|c|c|c|c|c|c|c|}
\hline \multirow{2}{*}{ Semster } & \multicolumn{2}{|c|}{ Anatomy } & \multicolumn{2}{|c|}{ Biochemist } & \multicolumn{2}{|c|}{ Microbilo } & \multicolumn{2}{|c|}{ Pathology } & \multicolumn{2}{|c|}{ Pharmaco } & \multicolumn{2}{|c|}{ Physiolo } & \multicolumn{2}{|c|}{ Com. Med. } & \multicolumn{2}{|c|}{ Others } & \multirow{2}{*}{$\begin{array}{l}\text { Total } \\
\text { Hours }\end{array}$} \\
\hline & $\mathrm{T}$ & $P$ & $\mathrm{~T}$ & $P$ & $\mathrm{~T}$ & $P$ & $\mathrm{~T}$ & $\mathrm{P}$ & $\mathrm{T}$ & $P$ & $\mathrm{~T}$ & $P$ & $\mathrm{~T}$ & $\mathrm{P}$ & MI & $\mathrm{CM}$ & \\
\hline Phase I* & 218 & 160 & 109 & 80 & 108 & 80 & 218 & 160 & 218 & 160 & 218 & 160 & 175 & 550 & 0 & 297 & 2911 \\
\hline
\end{tabular}

The calculation of the basic sciences is in an integrated manner though not implemented as such.

\section{Basic Sciences $=1889$}

Clinical Sciences $=5209$

Total Hours $=7098$

Basic Science Total Theory 1089 total Practical 800

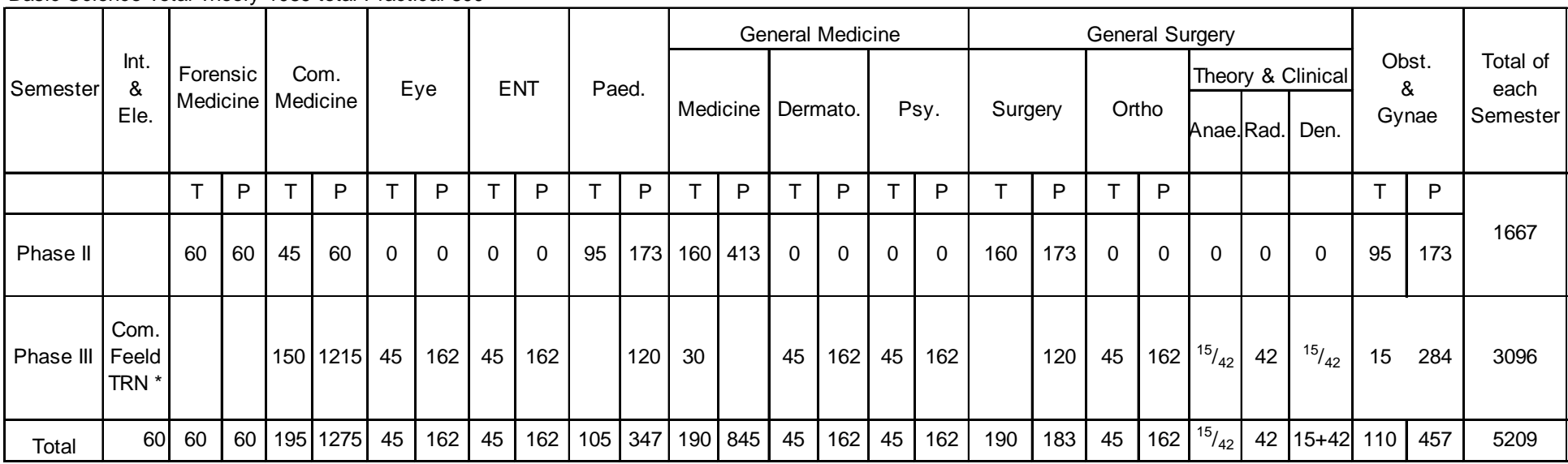

\section{Clinical 5988 hours in 5 semesters.}

* A major component of clinical experience is done during phase 3 when students go to the field and are given more exposure in internal medicine, surgery, obstetrics \& gynaecology and paediatrics 
